\title{
PROBLEMÁTICA DE LA ALTERIDAD EN ROBINSON CRUSOE DE DANIEL DEFOE Y “ADIÓS ROBINSON” DE JULIO CORTÁZAR'
}

\author{
POR \\ Tatiana CALDERÓn Le JolifF \\ Pontificia Universidad Católica de Valparaíso
}

El presente trabajo se aboca a analizar el tratamiento de la alteridad en el mito de Robinson Crusoe. Surgiendo en el periodo de la Ilustración, el mito de Robinson Crusoe pertenece a los grandes mitos modernos de la literatura occidental como Don Quijote, Fausto y Don Juan que comparten según Ian Watt las características de proeza y de exceso. Robinson logra la proeza de sobrevivir en una isla desierta pero pone de manifiesto un egocentrismo desmesurado (86). Jean-Paul Engélibert, autor de La Postéritéde Robinson Crusoé: un mythe littéraire de la modernité, 1954-1986, recalca la articulación en la robinsonnade francesa e inglesa de significaciones sociales, económicas, políticas con un contenido religioso o metafísico "qui expliquent ou justifient, ou bien critiquent et dénoncent, en tout cas interrogent, la condition de l'homme dans le monde, face à autrui, face a un fondement transcendant, face à lui-même" (234). El mito de Robinson Crusoe otorga efectivamente un lugar sobresaliente a la búsqueda de la identidad y a la experiencia de la alteridad. Este último concepto consta de una delimitación compleja con matices y perspectivas múltiples según los ámbitos del conocimiento en qué está considerado. Una aprehensión sencilla sería examinar el otro en relación al yo. La alteridad es el carácter de lo que es otro, pero también de lo que se altera. Esta noción establece una dialéctica con la identidad cuyas características contemplan la permanencia y la esencia. La alteridad puede también surgir desde una heterotopía. En el mito de Robinson, la isla representa una alteridad radical, un otro lugar absoluto, mientras que América constituye el otro lugar relativo (Engélibert 120). Peter Hulme subraya que la isla reduce a una esencia el crisol de complejidades presente en el continente. Permite

\footnotetext{
1 Este artículo forma parte de mi investigación postdoctoral, becada por la Universidad de la Frontera en Temuco, titulada "La alteridad en el mito de Robinson Crusoe: estudio comparativo en la literatura anglosajona, francesa y latinoamericana" (2010-2011). Me aboco esencialmente a las siguientes reescrituras contemporáneas: Robinson (1958) de Muriel Spark, Foe (1986) de J.M. Coetzee, Suzanne et le Pacifique (1921) de Jean Giraudoux, Viernes o los limbos del Pacifico (1967) de Michel Tournier y La isla de Robinson (1981) de Arturo Uslar-Pietri.
} 
una reflexión sobre la sociedad así como, en el caso de Robinson Crusoe de Daniel Defoe, la implementación de un discurso colonialista.

En La conquista de América, Tzvetan Todorov analiza la problemática del otro en Latinoamérica y delimita tres ejes de conocimiento:

Primero, hay un juicio de valor (un plano axiológico): el otro es bueno o malo, lo quiero o no lo quiero, o bien, como se prefiere decir en esa época, es mí igual o es inferior a mí (ya que por lo general, y eso es obvio, yo soy bueno, y me estimo...). En segundo lugar, está la acción de acercamiento o de alejamiento en relación con el otro (un plano praxeológico): adopto los valores del otro, me identifico con él; o asimilo el otro a mí, le impongo mi propia imagen; entre la sumisión al otro y la sumisión de otro hay un tercer punto, que es la neutralidad o indiferencia. En tercer lugar, conozco o ignoro la identidad del otro (éste sería un plano epistémico); evidentemente no hay aquí ningún absoluto, sino una gradación infinita entre los estados de conocimiento menos o más elevados. (195)

En los textos estudiados, la reflexión sobre el otro está estrechamente ligada a una consideración sobre los desplazamientos efectuados en la dicotomía civilización barbarie, e interroga el grado de exotismo de los autores. Robinson Crusoe, como relato de viajes y puesta en escena de un lugar desconocido, pertenece a lo que el comparatista francés Jean-Marc Moura llama el exotismo literario que necesariamente convoca la construcción del otro. Dos posturas surgen esencialmente frente al descubrimiento de ese otro. En la primera postura, el otro aparece como un espejo invertido (estereotipo) o doble (reflejo). En la segunda, la alteridad es reconocida y aprehendida en todo su hermetismo, sin voluntad de pasar en forma literal por el filtro de una visión etnocentrista. En el texto fuente de Daniel Defoe, la alteridad emerge progresivamente desde la visión de los caníbales a la distancia, la pisada en la arena, hasta la salvación del salvaje de sus congéneres caníbales y la vivencia de Robinson con el ahora bautizado Viernes.

Apartir de esta problemática presente en el texto fuente, me interesa examinar cómo ha evolucionado la relación Robinson/Viernes en las reescrituras posteriores, especialmente del siglo xx, en diversas aéreas culturales incluyendo -y eso es una nueva perspectivauna reescritura latinoamericana. En el presente análisis, apoyándome en el texto fuente de Defoe, me enfocaré en desentrañar las modalidades y la función de la relación en “Adiós Robinson", primera obra radial del escritor argentino Julio Cortázar. Escrita en 1977, la pieza radiofónica constituye un encargo del periodista español Ricardo Bada que en aquella época trabaja en Alemania para la Radio Deutsche Welle. Su proyecto radica en la realización de una serie de programas cuyo objetivo es reflexionar acerca de los espacios que la literatura universal ha consagrado. El archipiélago Juan Fernández, espacio donde fue relegado de 1704 a 1709 el marinero escocés Alexander Selkirk y uno de los lugares de referencia para la invención novelesca de Daniel Defoe, corresponde

Revista Iberoamericana, Vol. LXXIX, Núms. 244-245, Julio-Diciembre 2013, 843-862 ISSN 0034-9631 (Impreso) ISSN 2154-4794 (Electrónico) al cuestionamiento de Bada y deriva en la escritura de "Adiós Robinson". El programa, según el periodista, fue transmitido en diversas emisoras en todo el mundo, especialmente en América Latina, pero también en África, Asia, Estados Unidos, Canadá, Australia Nueva Zelandia, y Holanda. ${ }^{2}$ En 1984, la Editorial Katún publica en México el guión radiofónico, reeditado en forma póstuma en 1995 por Alfaguara en Madrid.

No se trata aquí de examinar las características del género radiofónico ${ }^{3}-$ me concentraré en el análisis textual del guión radiofónico- pero conviene señalar que Cortázar, al elegir un género "menor", destinado a ser escuchado por un número considerable de oyentes (implicando diversidad social y cultural) y no leído, persigue un objetivo singular que coincide con su compromiso político de la época, radicado en el socialismo:

Comprendí que el socialismo, que hasta entonces me había parecido una corriente histórica aceptable e incluso necesaria, era la única corriente de los tiempos modernos que se basaba en el hecho humano esencial, en el ethos tan elemental como ignorado por las sociedades en que me tocaba vivir, en el simple, inconcebiblemente difícil y simple principio de que la humanidad empezará verdaderamente a merecer su nombre el día en que haya cesado la explotación del hombre por el hombre. $(1994,37)$

En los años 1970, cuando América Latina está sufriendo la instauración de diversos regímenes totalitarios, Cortázar busca trasmitir un mensaje masivo con la reescritura de mito así como eludir la censura y los ataques a la libertad de expresión. La elección del género radiofónico corresponde a su afán de borrar los límites establecidos entre cultura alta y baja y de llegar a un público multitudinario. En Nicaragua, tan violentamente dulce, destaca esta intención: “[...] nuestro quehacer [...] consiste [...] en proyectarnos [...] al escenario latinoamericano, físicamente cuando es posible, o bien dando a nuestros trabajos nuevas características de difusión que [...] los inserten más y mejor en aquellos núcleos para quienes pueden ser útiles" $(1983,80)$. Esta elección concuerda también con la parodia del modelo moderno y de su industria cultural dirigida a las masas de la cual el radioteatro participa (Terrero 1). El humor de Cortázar y el estilo sencillo y directo de la pieza le permiten entregar un mensaje constando de varios niveles interpretativos que se ajusta a la diversidad del público. Pero lo esencial para el autor es crear un impacto en los oyentes generando una conciencia reflexiva sobre su propia realidad. Patricia Terrero observa que, en Argentina, la radio constituye uno de

\footnotetext{
Estas precisiones provienen de un intercambio de correos electrónicos entre Patricia Carrera, en el marco de su investigación sobre el radioteatro a través de la obra de Julio Cortázar, y el periodista Ricardo Bada. Para este aspecto, se puede consultar en línea la tesis de grado master, Análisis del radioteatro a través de la obra de Julio Cortázar: “Adiós, Robinson” (2010), de Patricia Carrera cuyo objetivo es aborda precisamente la dimension genérica de la obra de Cortázar. <https://papyrus.bib.umontreal.ca/jspui/ bitstream/1866/4396/2/Carrera_Silvia_P_2010_memoire.pdf.pdf $>$.
}

Revista Iberoamericana, Vol. LXXIX, Núms. 244-245, Julio-Diciembre 2013, 843-862 ISSN 0034-9631 (Impreso) ISSN 2154-4794 (Electrónico) 
los medios de comunicación que revela la identidad social y cultural de la clase popular a partir de arquetipos provenientes del imaginario colectivo y de géneros de la cultura masiva internacional. Asimismo, las décadas de 1960 y 1970, caracterizadas por la difusión internacional de la cultura, corresponden también a un periodo durante el cual la juventud reivindica un ideal revolucionario ligado, en el caso latinoamericano, a la liberación de los pueblos del yugo neocolonial.

La relación Robinson/Viernes que se desenvuelve en la isla desierta aparece como un paradigma del encuentro con el otro y de su sometimiento, y por lo tanto, se inserta en esta reflexión sobre la liberación. Me parece fructífero enunciar e indagar en los mecanismos de dominación del discurso colonial y postcolonial en los dos textos mencionados. En el mito de Robinson particularmente, aparece una tensión entre e mito del buen salvaje y la problemática del canibalismo, tropo cristalizando lo abyecto.

En Robinson Crusoe (1719), el autor británico Daniel Defoe cuenta las aventuras de un hombre caracterizado por su perseverancia, su ingenio, su dinamismo emprendedor, y su espíritu utilitario. Daniel Defoe escribe un relato novelesco que se presenta como una autobiografía real escrita en la primera persona por el personaje epónimo Robinson Crusoe. Este relato está puesto en abismo en el log-book, el diario íntimo que escribe en la isla. La elección de un narrador autodiegético es fundamental al describir la alteridad. Defoe compone su texto en el siglo XVIII cuando Inglaterra está confirmando su hegemonía como gran potencia económica, marítima y comercial. Las Actas de Navegación elaboradas en el siglo anterior para proteger el comercio inglés, así como la fundación del Banco de Inglaterra y la penetración colonial en India, Norteamérica y las Antillas, asentaron su poder económico. Las aventuras de Robinson se desenvuelven en la segunda mitad del siglo XVII. El joven Robinson vive en una familia de clase media cuya aspiración es transformarlo en un honesto hombre, un puritano moderado. Sin embargo, desobedece a su padre que lo destina a la abogacía e inicia una vida de aventuras. En una de ellas, es tomado prisionero y se convierte en el esclavo de un turco, condición pasajera que nunca se cuestionará a la hora de someter a Viernes. Logra escapar y encuentra la prosperidad en Brasil donde aprende progresivamente diversas profesiones y termina administrando una plantación de azúcar. Insatisfecho con el rendimiento de su plantación decide ir en busca de esclavos. Por lo tanto, el beneficio constituye el motivo esencia de su viaje. Nunca llegará a su destino. Naufraga en una isla desierta, situada, según él, frente a la desembocadura del Orinoco y la bautiza isla de la desesperación. La gran proeza de Robinson es lograr usar las herramientas de la civilización (encontradas en el barco encallado) para sobrevivir y hasta construir un semblante de orden civilizado en la isla. El autodidacta Robinson se convierte en carpintero, labrador, sastre, cocinero... La dignidad del trabajo es fundamental y se atiene a los valores del puritanismo que promueve el personaje al igual que su pudor excesivo y la ausencia del deseo carnal.

El encuentro con la alteridad es progresivo. Primero, especula sobre el encuentro con los caníbales que observa a la distancia y muestra un terror desmesurado al ver

Revista Iberoamericana, Vol. LXXIX, Núms. 244-245, Julio-Diciembre 2013, 843-862 ISSN 0034-9631 (Impreso) ISSN 2154-4794 (Electrónico) una pisada en la arena. El encuentro efectivo con el otro está precedido por un sueño premonitorio en el que Robinson prevé la dominación inmediata del salvaje. Así, a la hora de salvarlo, Robinson ya ha construido el relato del rescate del indígena que condiciona su aprehensión del caníbal. Comienza luego su vivencia con el salvaje que denomina Viernes, según el día de la semana en que lo encontró. Viernes es por lo tanto reducido en forma inmediata y sin cuestionamiento a la esclavitud, así como sufre la negación de su identidad. Encarna por consecuente al colonizado sometido y sumiso. Robinson a su vez representa al colonizador dinámico y productivo. Su encuentro con Viernes, hito situado en el último tercio de la obra, después de haber estado veinticuatro años solo en la isla, le permitirá desarrollar una suerte de colonia, "mi antigua casa me pareció una colonia perfecta" (104) y librarlo de la soledad. El caníbal arrepentido (según Robinson) permitirá al final su salvación ya que le facilitará la salida de la isla. Por ende, y aunque existan intersticios en los cuales aparece una puesta en jaque relativa del discurso colonial, Robinson permanece con sus certidumbres y nunca cuestiona su supremacía sobre el indígena.

No obstante, Crusoe es también un ser contradictorio, temeroso, violento, carcomido por la culpa y carente de comprensión de sí. Encarna "the modernity of European consciousness shipwrecked in the Caribbean, the very archipelago of its subversion" (Hulme 215). Francis Affergan, en su artículo "Les marqueurs de l'autre dans Robinson Crusoe: Contribution a la genèse de l'anthropologie de l'altérité”, enuncia el lugar del otro en la ficción de Defoe: “Tantôt l'autre n'est rien face à Robinson qui est l'Absolu, tantôt il incarne une valeur mais moindre que celle qu'incarne le narrateur. Dans les deux cas, l'altérité se trouve élimée au profit d'une série de différences qui en valident la manipulation et en mesurent la relativité" (39). Efectivamente, Viernes, como lo veré más adelante, adquiere los rasgos físicos de un europeo en la visión de Robinson que necesita considerarlo como un individuo digno de ser instruido y acompañado por él. No obstante, en ningún momento lo libera de su condición de esclavo. Aparece entonces la contradicción de una gemelidad construida por Robinson, una gemelidad fragmentada e irracional que anula en forma ficticia la alteridad.

La reapropiación del mito por autores latinoamericanos evidencia un discurso producido desde la alteridad o más bien desde el mestizaje. ${ }^{4}$ Carlos A. Jáuregui en su libro, Canibalia: canibalismo, calibanismo, antropofagia cultural y consumo en América Latina (2005) estudia el continente latinoamericano a través del tropo del canibalismo. El crítico observa cómo el canibalismo comporta una manera de entender al otro. Es un tropo que hace surgir el miedo de la disolución de la identidad (14). Más que un tropo en realidad, constituye una heterotropía, una figura de lengua que

Arturo Uslar-Pietri, en la novela histórica La isla de Robinson, retoma el mito desde el personaje emblemático de Simón Rodríguez, preceptor de Simón Bolívar.

Revista Iberoamericana, Vol. LXXIX, Núms. 244-245, Julio-Diciembre 2013, 843-862 ISSN 0034-9631 (Impreso) ISSN 2154-4794 (Electrónico) 
define al otro. El crítico no pretende aseverar una realidad sino más bien examinar el canibalismo como una metáfora. El canibalismo es un signo palimpséstico producto de diversas economías simbólicas y procesos históricos (17). Canibalia compone un espacio geográfico que representa a la vez la imagen del monstruo americano y el cuerpo fragmentado y devorado por el colonialismo. El continente latinoamericano puede también ser considerado como una isla dependiendo constantemente, durante la conquista, de las reglas establecidas en España. Canibalia es una mirada cartográfica a otro. El caníbal es un constructo colonial que tiene más sentido aún en la escritura de Cortázar que parodia esta identificación simplista. Me parece así fundamental analizar con detención la pieza radiofónica "Adiós Robinson" de Julio Cortázar -desatendida por los estudiosos del autor- que escribe desde la postura del otro, en una perspectiva posmodernista que, según la acepción de Frederic Jameson, es "una concepción que permite la presencia y coexistencia de una gama de rasgos muy diferentes e incluso subordinados entre sí" (16). El posmodernismo tiene como atributos principales la presencia de una nueva superficialidad que se puede reflejar en la cultura de la imagen o en el simulacro y en el debilitamiento de la historicidad provocando en algunos casos una percepción esquizofrénica. Estos dos rasgos se pueden apreciar en la pieza radiofónica de Cortázar que postula una manera distinta de transmitir la movilidad escurridiza de mundo, en soportes culturales adaptados a la realidad del siglo xx: “[ ...] hay que superar la vieja noción de lo cultural como un bien inmueble e intentar lo imposible para que se convierta en un bien mueble, en un elemento de la vida colectiva que se ofrezca, se dé y se tome, se trueque y se modifique, tal como lo hacemos como los bienes de consumo, con el pan, y las bicicletas, y los zapatos" $(1983,81)$.

El "ex-colonizado" se apropia entonces el mito occidental para denunciar y deconstruir su ideología primitiva. Al hablar de la creación de "Adiós Robinson" en una carta a Ricardo Bada ${ }^{5}$, Cortázar explicita la relación entre el mito de Robinson y su reflexión sobre la realidad latinoamericana: "Je crois que l'idée centrale est bonne, écologique, déontologique, "contestataire" et très actuelle, et que nous les latinoaméricains nous devons la trouver sympathique pour des raisons évidentes : nous sommes tous un peu Vendredi". Además de participar a la parodia del mito, la elección del género radiofónico tiene otra función. Adscrita al género dramatúrgico, "Adiós Robinson" permite el surgimiento de voces independientes. Viernes puede expresarse sin el filtro de la mirada de Robinson propio del texto fuente. Puede dejar fluir su consciencia sin manipulaciones fantaseantes. En el texto, Robinson y Viernes del siglo xx vuelven en un avión a la isla dejada en el siglo xvII, situación que indica un salto temporal irrea de cuatro siglos. El propósito de Cortázar parece entonces residir en el relato de las consecuencias de la colonización de Robinson. Su texto es una "secuela" de las aventuras

\footnotetext{
${ }_{5}$ Carta enviada en septiembre de 1977, consultar http://via.expresa.free.fr/adios.htm.
}

Revista Iberoamericana, Vol. LXXIX, Núms. 244-245, Julio-Diciembre 2013, 843-862 ISSN 0034-9631 (Impreso) ISSN 2154-4794 (Electrónico) originarias de Robinson trasportado al mundo contemporáneo. Sobrevolando la isla de Juan Fernández, observan que se ha convertido en una ciudad ultramoderna. Robinson se emociona a la manera de un niño al ver los cambios de "su" isla. Está maravillado por los progresos técnicos. La primera tensión surge en la actitud de Viernes cada vez que contesta a Robinson llamándole "amo" seguido de una risa nerviosa. Otra tensión se percibe en los habitantes de la isla que se rehúsan a ver Robinson. Al parecer, lo que representa ya no corresponde a la realidad. En cambio, Viernes logra integrarse completamente a la isla renovada pero aparece como un personaje extremadamente ambivalente: sometido y poderoso a la vez.

En primer lugar, me enfocaré en la visión que tiene Robinson del otro. ¿Cómo juzga y percibe a Viernes en su primer encuentro? ¿Cómo se implementa la relación de dominación? ¿Cuáles son las herramientas que usa para establecerla? Seguiré, en un segundo momento, con las estrategias de resistencia de Viernes que aparecen esencialmente en las reescrituras producidas en el siglo xx. Viernes se transforma en un personaje subversivo e independiente dentro de un mundo civilizado deficiente y agrietado. En tercer lugar, veré como se instaura una inversión relativa de las relaciones de dominación. Viernes se convierte en un personaje imperante mientras que Robinson y el mundo que encarna devienen obsoletos. Para terminar, se analizará la permanencia del enigma a pesar de los intentos por parte de los personajes de entablar un diálogo con el otro para así poder conocer su historia.

I. LA EPIFANÍA DEL ROSTRO DEL OTRO: LA MIRADA DE ROBINSON

1. El primer encuentro con el otro

C'est lorsque vous voyez un nez, des yeux, un front, un menton, et que vous pouvez les décrire, que vous vous tournez vers autrui comme vers un objet. La meilleure manière de rencontrer autrui, c'est de ne pas même remarquer la couleur de ses yeux ! Quand on observe la couleur des yeux, on n'est pas en relation sociale avec autrui. La relation avec le visage peut certes être dominée par la perception, mais ce qui est spécifiquement visage, c'est ce qui ne s'y réduit pas. (Lévinas 5)

Emmanuel Lévinas describe el acceso al rostro como un acto ético. El verdadero encuentro con la otredad no pasa por la superficialidad del rostro sino que por la intención escondida. En los textos, es interesante observar que justamente el encuentro con el otro pasa en primer lugar por la aparición y descripción del rostro. En Defoe, la presentación de Viernes es a la vez emblemática y ambigua. Viernes es un caníbal. Al ver los grupos de caníbales a la distancia, Robinson los relega a lo abyecto. Peter Hulme subraya en Robinson el miedo representado por la presencia de los caníbales. La construcción del fuerte para protegerse de los caníbales y el terremoto que sacude más tarde la isla hacen

Revista Iberoamericana, Vol. LXXIX, Núms. 244-245, Julio-Diciembre 2013, 843-862 ISSN 0034-9631 (1) ISSN 2154-4794 (Electrónico) 
emerger el miedo a ser tragado. Está asociado a la dispersión del cuerpo, a la disolución de su integridad. Según la hipótesis del crítico, esta fragmentación, considerada bajo los parámetros de la religión judeo-cristiana, impediría la resurrección del cuerpo en el juicio final. El canibalismo representa así el tabú moral de la sociedad occidental y cristiana. Sin embargo, cuando Robinson salva a Viernes, tiene que superar su repulsión para poder alcanzar su propósito de apropiación que condiciona su sobrevivencia y por último su salvación. Para erradicar el tabú, retrata al salvaje como un ser delicado, con un rostro que contiene rasgos de la suavidad europea. Tiene la frente amplia, la mirada inteligente, los dientes blancos, una tez delicada opuesta a la de los negros (aún más degradados en la novela). Robinson proyecta en Viernes un físico similar al europeo para mejor negar su identidad. No ve a Viernes sino a un doble disminuido que por lo tanto puede ser su ayudante o compañero sin cesar de ser su esclavo.

El retrato del otro en las reescrituras del mito oscila regularmente entre la complacencia y la repulsión. En Cortázar, la intriga se desenvuelve en el siglo xx, por lo tanto el texto no se detiene en una descripción exhaustiva del primer encuentro con el otro ocurrido cuatro siglos antes. Sin embargo, aparecen varias referencias a la estadía de los dos personajes en la isla del siglo XVII, época en la cual Viernes encarnaba el "caníbal malo": "Sí, amo (risita), se ve muy bien la costa donde casi me comen esos caníbales malos, y eso solamente porque antes mi tribu había querido comérselos a ellos, pero así es la vida, como dice el tango" (149). Situada en los primeros intercambios entre Robinson y Viernes, cuando el avión aún no ha aterrizado, la frase indica la aparente docilidad de Viernes que se traduce, entre otras cosas, por un lenguaje sencillo y maniqueo. La imagen del caníbal reviste su visión estereotipada y repulsiva. Viernes vuelve al lugar de sometimiento y de proceso civilizatorio. Cumple con la función de constructo colonial de justificación de la explotación de los indígenas, subrayado por Carlos Jáuregui. Sin embargo, ya aparece una subversión del locutor que introduce un matiz cultural argentino y una suerte de relativismo cultural. Viernes está todavía siguiendo el juego de Robinson y aparenta seguir sus pautas interpretativas. Más adelante, se transforma el lenguaje y el discurso de Viernes deviniendo sofisticado, argumentativo y poético. La única descripción física del "caníbal" que aparece en el relato aparece con la mención de los pulgares largos que permiten a Plátano y Viernes reconocerse como miembros de una misma tribu y que remiten a la alteridad radical postulada por el discurso colonialista. En varias reescrituras, el primer encuentro entre Robinson y Viernes pasa por el rostro e indica el liminal desencuentro. En Cortázar, después del primer contacto visual, la palabra, manipulada en primera instancia por el colonizador, se convierte en una herramienta del colonizado.

\section{La lengua impuesta de Robinson}

La problemática de la lengua es esencial en el mito y en la construcción del discurso colonial. En Daniel Defoe, cuando Robinson escucha los caníbales, sólo percibe sonidos. No intenta en ningún momento entender el otro lenguaje que simplemente no existe para él. En cambio, las dos primeras palabras que enseña a su esclavo son "amo" y "Viernes". Así, implementa una relación jerárquica de dominación inmediata y rechaza la identidad del indígena dándole un nombre ajeno a los nombres "cristianos" usualmente utilizados. Lo degrada aún más identificándole con un día de la semana sin que esto sea el objeto de un cuestionamiento. Viernes aprenderá progresivamente a hablar pero quedará siempre en desventaja para expresar su cosmovisión con eficacia.

En “Adiós Robinson”, Viernes muestra progresivamente un manejo complejo del lenguaje impuesto. Recalca con una cierta amargura y humor la imposición del inglés al mundo entero: "Ustedes han hecho bien las cosas, amo, esa lengua la hablan hasta las focas del Ártico" (191). Robinson simula tener una relación cordial con Viernes. En realidad, no soporta cuando el otro lo trata con familiaridad: "¿Quién te ha autorizado para que me llames por mi nombre de pila?” (203). Robinson, personaje emblemático de la modernidad, se inserta en un mundo posmoderno cuyos códigos le son extraños. Todavía alardea de superioridad y no acepta compartir con un criado: “¡Ah, Viernes, hay cosas que los indios como tú no pueden comprender a pesar de lo mucho que los ayudamos a diplomarse en las mejores universidades!"(181). Lo que no entiende todavía Robinson es que su discurso ha caducado. Viernes ha aprendido a defender su postura, fortalecida por su identidad bicultural impuesta.

\section{La importancia del "libro"}

La crítica poscolonial recalca la importancia de la textualidad en el proceso de colonización. En "Signos tomados por prodigios", Homi Bhabha ve el libro inglés como insignia de la autoridad colonial y significante del deseo y la disciplina colonial. La noción de hibridez trabajada por Bhabha me parece particularmente interesante en la relación de Robinson y de Viernes al libro: "Si la aparición del libro inglés es leída como una producción de hibridez colonial, entonces ya no dispone simplemente de autoridad. Da nacimiento a una serie de cuestionamientos a la autoridad" (142). La hibridez contamina todos los espacios discursivos e impide una paz unitaria, lo que la hace amenazante. Bhabha destaca la dificultad de la postura híbrida del colono: "Pues el deseo del discurso colonial es una escisión de la hibridez que es menos uno y doble; y si eso suena enigmático es porque su explicación tiene que presentar sus respetos a la autoridad de esas prudentes preguntas que hacen los nativos, con tanta insistencia, al libro inglés" (145). En Daniel Defoe, dos escritos aparecen: la Biblia y el log-book en proceso de escritura. La Biblia aparece como un libro esencial y omnipresente
Revista Iberoamericana, Vol. LXXIX, Núms. 244-245, Julio-Diciembre 2013, 843-862 ISSN 0034-9631 (Impreso)
Revista Iberoamericana, Vol. LXXIX, Núms. 244-245, Julio-Diciembre 2013, 843-862 ISSN 0034-9631 (Impreso) 
que sirve de apoyo y de consuelo a Robinson. Éste se impone su lectura diaria para impregnarse de su mensaje y alcanzar la fe. Le permite también, junto con el trabajo, tolerar la soledad. Vemos sin embargo que Robinson es un puritano que no conoce $n$ los preceptos: "No tenía, ¡ay! Instrucción religiosa; de todo lo que la bondad de mi padre me había inculcado apenas quedaba nada tras ocho años de errantes extravíos y continuo contacto con aquellos que, como yo, eran malos y profanos en máximo grado" (98-99), ni parece nunca alcanzar la revelación. Dios le causa espanto y culpabilidad. Robinson no ha seguido las pautas inculcadas por su padre en su juventud y siente que su estadía en la isla es la consecuencia de su "depravación" y de su impulso hacia las aventuras. Se entiende entonces la isla como un lugar de expiación y de redención. Sin embargo, a la hora de enseñar a Viernes su conocimiento, se encuentra desestabilizado por las preguntas ingenuas y lógicas de su esclavo. Ian Watt interpreta la evolución de Robinson a nivel espiritual como un puritanismo sin la fe.

Julio Cortázar no juega directamente con la dimensión libresca de la Biblia pero sí con el texto fuente de Defoe y su dimensión moral. Sirve de referencia constante para indicar los cambios ocurridos en la isla, en el comportamiento de Viernes (caníbal malo en el libro de referencia) y de Robinson. Permite también reflexionar sobre el sentimiento de soledad. Robinson, en Cortázar, siente con mayor intensidad la soledad. En el libro del autor británico, Robinson encarna el emprendedor que logra superar de alguna manera la soledad con el trabajo mientras que en "Adiós Robinson", es un personaje periférico, encarcelado, relegado en el pasado. Robinson sufre el desengaño pensando haber mostrado en su libro "el pavor de la soledad y la hermosura de la reunión, del contacto..." (162) pero viendo que el contacto se ha vuelto hermético y que la indiferencia se ha convertido en una regla de vida.

\section{LAS ESTRATEGIAS DE RESISTENCIA Y FRAGMENTACIÓN DE UN MUNDO: VIERNES SUBVERSIVO}

En las reescrituras contemporáneas, Viernes ya no representa un elemento conciliador y conforme a la ideología colonialista sino un componente subversivo carcomiendo progresivamente o violentamente el orden establecido por Robinson. En Cortázar, Viernes muestra estrategias de resistencia que acentúan la marginalización ya establecida por Robinson.

\section{La risa de Viernes en Cortázar: entre falsa sumisión y transgresión}

La risa aparece como una otra herramienta de subversión en “Adiós Robinson”. Una interpretación parcial tendería en ver la risa de Viernes como el fruto de un traumatismo. Cada vez que Viernes responde a Robinson con la palabra amo que éste le impuso, surge una risita nerviosa indicada como acotación. Robinson, irritado, le interroga sobre la razón de tal manifestación:

Revista Iberoamericana, Vol. LXXIX, Núms. 244-245, Julio-Diciembre 2013, 843-862 ISSN 0034-9631 (Impreso) ISSN 2154-4794 (Electrónico)
ROBINSON: [...] ¿Se puede saber qué tiene de gracioso que yo sea tu amo, el hombre que te salvó de un destino horroroso y te enseñó a vivir como un ser civilizado?

VIERNES: Laverdad, no tiene nada de gracioso, amo (risita). Yo tampoco comprendo muy bien, es algo completamente involuntario, créeme. He consultado a dos psicoanalistas, uno freudiano y uno junguiano para doblar las chances como hacemos en el hipódromo, y para mayor seguridad me hice examinar por una eminencia de la contra-psiquiatría. Dicho sea de paso, éste fue el único que aceptó sin duda que yo fuera Viernes, el de tu libro.

ROBINSON: ¿Y cuál fue el diagnóstico?

VIERNES: Todavía está en procesamiento electrónico en Dallas, pero según me informó Jacques Lacan el otro día, se puede sospechar desde ya que se trata de un tic nervioso (150).

Aquí, con un discurso hegemónico y tajante, Robinson enfatiza inmediatamente en la legitimidad de su dominación, en la justificación de tal relación y en el aporte indiscutible de su cultura. Viernes sigue todavía la tónica instaurada por Robinson y muestra su aparente docilidad disculpándose e intentando explicar la razón de tal disturbio interno. Su respuesta indica la falsedad de su sumisión introduciendo una exageración sospechosa con sus referencias múltiples al psicoanálisis. Revela igualmente la permanente reflexión sobre ficción y realidad subyacente al libro de Defoe y alude a la posibilidad de una farsa. Consta también de elementos de invención heterogénea que no solamente muestra un arreglo posmoderno de temporalidades y planos narrativos sino que también tiende a mostrar el elemento traumático de la risa de Viernes. Acceder a la terapia es aceptar el malestar. Sin embargo, a la vez que Cortázar parece denunciar la imposición sufrida por Viernes, introduce una ironía o al menos un aspecto humorístico que derrumba el argumento. El procesamiento electrónico en Dallas claramente introduce un elemento heterogéneo y la parodia en la denuncia. La risa no solamente muestra un rasgo de la fragmentación sentida por Viernes sino que se convierte en una herramienta de transgresión. La risa desestabiliza a Robinson y provoca su desasosiego. Está también asociada con el cambio que Viernes hace surgir. Si bien, en un primer instante, se conserva en apariencia el lazo jerárquico amo/esclavo, rápidamente Viernes con su risa y con el tuteo, neutraliza e iguala la relación. Al desaparecer la relación de dominación, es decir, cuando Viernes llama a Robinson por su nombre y lo tutea, éste reacciona en forma violenta. El evento permite no obstante a Viernes dar cuenta del desfase de Robinson con la realidad y emprender una reflexión sobre lo que su historia representa: "Es cierto, Robinson. Muchas cosas cambiaron en ese momento. Y no es nada al lado de lo que todavía va a cambiar" (167). Viernes aparece como un personaje más lúcido y sabio, en cierta medida, profético o más bien reflexivo. Desde su postura subalterna, consta de rasgos adaptativos. Aprendió el lenguaje de Robinson, se plegó a sus códigos sin perder

Revista Iberoamericana, Vol. LXXIX, Núms. 244-245, Julio-Diciembre 2013,843-862 ISSN 0034-96314 ISSN 2154-4794 (Electrónico) 
su propia identidad que el colono le arrebató pero que él siguió alimentando tal como lo muestra su relación con Plátano. La risa entonces puede ser considerada tanto como una manifestación del traumatismo del colonialismo impuesto por Cortázar como un elemento de subversión del orden robinsoniano. Así, en la obra, la risa caracteriza un elemento transgresor y permite el surgimiento de una expresión identitaria que juega con el propio estereotipo. En varias reescrituras, la risa caracteriza al salvaje, perezoso y vividor. La risa constituye entonces una herramienta para fijar la identidad del caníbal a la vez que destruye el sistema impuesto por Robinson. Henri Bergson en "La Rire. Essai sur la signification du comique" ve la risa como la protestación de la vida contra la mecánica que la amenaza (30). El mecanismo superpuesto a la naturaleza crea un desfase que provoca la risa. En Cortázar, la risa de Viernes no es franca ni espontánea. Es nerviosa y cerrada e indica la vigencia de la opresión.

\section{El baile y la música: la independencia de Viernes}

Si la risa permite irrumpir y quebrar las certidumbres de Robinson, otros elementos como el baile, la música y la dimensión aérea aparecen en las reescrituras como manifestaciones de la identidad de Viernes. En Cortázar, al volver a la isla, Robinson subraya la dimensión arielista de Viernes que ve como un joven sin las manchas de la historia "más cerca que yo del aire y los astros y los otros hombres..." (169). Cuando Viernes le recuerda que era un caníbal y que según sus valores cristianos era una seña de ignominia, se establece un diálogo intertextual con "De los caníbales" de Montaigne. Robinson muestra otra visión del canibalismo: "No importa. Lo mismo estaban más cerca los unos de los otros. Hay muchas maneras de ser caníbal, ahora lo veo con tanta claridad" (169). Recalca el canibalismo figurado de los propios europeos al someter violentamente los países conquistados. Viernes es un ser flexible que se opone a la rigidez de Robinson. Este último sabe que no puede cambiar, que su discurso normado y sedimentado por siglos de historia colonial no puede ser renegado porque representa un discurso que justifica su identidad.

Las estrategias de resistencia de Viernes para desligarse del lazo dominador de Robinson residen mayormente en herramientas que radican en el cuerpo, en ese cuerpo devorado por el colonialismo según Carlos Jáuregui, y en las emociones, salvo en Cortázar que pone en escena un Viernes con poder de habla y con una hábil apropiación de las herramientas discursivas de Europa mostrando así otro tipo de antropofagia. Viernes enfrenta a Robinson derrumbando su pretensión y su orgullo.

\section{VIERNES IMPERANTE Y ROBINSON OBSOLETO: VISIÓN CRÍTICA DE LA MODERNIDAD}

En Defoe, Robinson se caracteriza por sus certidumbres y la justificación divina de todas sus acciones. Uno de los pocos momentos de vacilación proviene de la pregunta

\footnotetext{
172 Revista Iberoamericana, Vol. LXXIX, Núms. 244-245, Julio-Diciembre 2013, 843-862

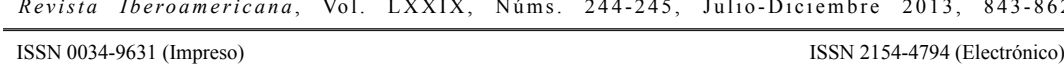

ingenua de Viernes acerca de la potencia real de Dios. Robinson, paternalista, quiere convertir el joven salvaje. Emprenden un diálogo donde por primera vez dónde Viernes presenta su cosmogonía con su Dios Benamuki. El inglés rápidamente descarta la importancia de tal visión y decide enseñarle la sabiduría de la verdadera religión. Expone así la predominancia de Dios sobre el diablo. Viernes entonces, con una lógica infalible, le pregunta: "Pero - declaró él-si Dios más poderoso, si Dios más fuerte, ¿Por qué no matar Dios al diablo y este así, no hacer más daño? [...] Me encontré sin saber que contestar, y fingiendo que no lo había entendido, le pedí que me repitiera su pregunta" (221). Aunque perturbado, Robinson no deja ver por mucho tiempo su incomodidad y rebate las dudas sin interrogarse. Termina justificando que al fin de los tiempos Dios castigará el diablo. Viernes no entiende la demora del castigo. Robinson le explica entonces que Dios permite a todos los hombres arrepentirse, y ser perdonados, justificación a la cual Viernes contesta: "Bien, bien, eso muy bien; entonces vos, yo, Diablo, todos malos, todos ser reservados, arrepentirse, y Dios perdonar a todos. Interrumpí entonces el diálogo, levantándome bruscamente como si me llamara alguna tarea urgente" (223). En la novela de Defoe, este evento constituye el único momento donde Robinson es incapaz de producir una respuesta argumentada y muestra su incertidumbre fugazmente. Deja sin embargo lugar a una reflexión compleja sobre la problemática y el origen del mal. En las reescrituras contemporáneas del mito, Viernes toma resueltamente el protagonismo y desestabiliza el discurso colonial. En la obra de Cortázar, Robinson se convierte en un personaje vetusto, caduco cuya rigidez le ha prohibido evolucionar y adaptarse a los cambios.

1. El náufrago de la historia: la modernidad disfuncional y fracasada

La marginalización de Robinson permite la aparición de la lucidez. Al principio de la pieza, Robinson malinterpreta todas las señales y cree genuinamente que los colonizados le agradecen su misión civilizadora, "su querida isla convertida en un paraíso moderno" (152) donde ya no queda un espacio de naturaleza. Al llegar al aeropuerto, alaba la perfección en su organización. En realidad, el orden se exacerba, deviene absurdo y termina por implementar la segregación: “ALTAVOZ: Atención pasajeros con destino a Buenos Aires. Al final del corredor marcado con flechas verdes, deberán dividirse en dos grupos: las damas a la izquierda y los caballeros a la derecha [...]" (184). Pero Robinson no ve las disfunciones del aeropuerto. Al llegar la funcionaria, el desengaño es vertiginoso. El rechazo de su presencia es tan rotundo que Robinson termina por darse cuenta de que los frutos de la modernidad, la exaltación del individualismo desembocaron en la emergencia de la soledad en la multitud. Es notable subrayar que mientras Robinson se entusiasma con la modernidad de la ciudad, con la muchedumbre, Viernes la encuentra igual a Londres 20 años atrás. La compara con Las Vegas, Singapur, São Paulo, Nueva York. Señala así (con un dejo de exageración) la homogeneización

Revista Iberoamericana, Vol. LXXIX, Núms. 244-245, Julio-Diciembre 2013, 843-862 ISSN 0034-9631 (Impreso) $\quad$ ISSN 2154-4794 (Electrónico) 
de las ciudades modernas. Viernes ha entendido los cambios profundos, mientras que Robinson tiene una comprensión superficial. La funcionaria anuncia a Robinson su imposibilidad de salir libremente en la isla por las tensiones existentes con el gobierno británico. Podemos atisbar una alusión al conflicto de las islas Malvinas entre el Reino Unido y la República Argentina directamente ligado a los procesos de colonización. Está en "su isla" y sin embargo no puede deambular, moverse libremente. Quiere ir de juerga con Viernes y Plátano pero las consignas lo tienen asignado a residencia salvo para visitas muy vigiladas y puntuales: ir al museo de la antropología, salir con un especialista en construcción para ir a admirar los edificios, etc. Está reducido a la observación pasiva de su obra constructora e intelectual. Ya no es un actor sino que un espectador de su propio mundo. Robinson sufre una profunda desilusión al ver el repudio que le reservan sus "hijos culturales por así decirlo" (163). Está encarcelado producto de sus propias consignas, en un mundo de reglas que lo asfixian. Robinson se siente más sólo en el gentío que en su soledad de antaño en la isla. Comparte su tristeza con Nora, la funcionaria esposa del subjefe de policía. Representa las autoridades que tienen que hacer respetar las reglas de la modernidad impuesta por Robinson. Sólo que ya no es una modernidad, sino que un mundo caracterizado por elementos heterogéneos y una percepción fragmentada del tiempo.

\section{Viernes redentor de la soledad y único capaz de escapar al sistema}

Viernes, junto con Plátano, son personajes libres gracias a su poder de adaptabilidad y de flexibilidad. Robinson se da cuenta que Viernes "era todavía capaz de escapar a lo que el sistema de Juan Fernández [le] impone a [él]” (164). Viernes entendió el sistema, se desliza dentro de sus códigos y se apropia lo que le parece provechoso. Robinson empieza a admirar el "caníbal mental", el "salvaje interior" que queda en Viernes, es decir su intrínseca libertad. En realidad, el salvaje domesticado se convierte en el antropófago reivindicado por el escritor vanguardista brasileño Oswald de Andrade. En su "Manifiesto Antropófago" (1928), el ensayista rescata la dimensión simbólica de la antropofagia brasileña. Ya no se trata de comer literalmente a su enemigo pero de proceder a una deglución crítica de lo ajeno, en este caso de la cultura europea. El antropófago valora la cultura indígena y se apodera de la cultura occidental. El hombre latinoamericano no se esclaviza ni niega al otro: lo engulle en un gesto afirmativo y lo transforma en un alimento para obtener una identidad propia. Viernes reviste las características del antropófago simbólico que es progresivamente reconocido por Robinson. Nora también se da cuenta de la preponderancia de Viernes: "NORA: -Ese Viernes agradecido y fiel, aprendiendo a vestirse, a comer con cubiertos, y a hablar en inglés, parecería que es él quien hubiera debido salvar a Robinson Crusoe de soledad. A Robinson y a mí, por supuesto, a mí y a todos los que nos reunimos en el lobby de hotel para beber un inútil trago recurrente y para ver nuestra propia tristeza en los ojos

17everista Iberoamericana, Vol. LXXIX, Núms. 244-245, Julio-Diciembre 2013, 843-862 \begin{tabular}{lll}
\hline ISSN 0034-9631 (Impreso) & ISSN 2154-4794 (Electrónico)
\end{tabular} del otro" (164). La confesión de Nora deja vislumbrar el fracaso de la modernidad según Robinson, una modernidad individualista y alienante. Sin embargo, si Viernes muestra libertad, no la comparte con Robinson que se da cuenta que no podrá cambiar y se resigna a la inmovilidad.

3. Despedida a la significación original del mito: diálogo deceptivo con el otro

Viernes y Nora terminan por despedir a Robinson. Según nuestras pesquisas previas, por primera vez en las reescrituras del mito, se otorga la palabra a Viernes que tiene la posibilidad de exponer su reflexión. Si en un primer instante, Viernes actúa como lo espera Robinson, es decir como el esclavo obediente, al ver que el inglés no reacciona frente a la evidencia, lo encara y le muestra las fallas estructurales de su discurso colonialista. Emerge entonces un intercambio verbal que constituye a la vez un diálogo en la medida que permite esclarecer los lazos de dominación pero se transforma en un no diálogo ya que se erige un muro de incomprensión y de apartamiento entre los dos hombres. Robinson considera que es "demasiado civilizado para aceptar que la gente como Viernes o como Plátano pueda hacer algo por mí, aparte de servirme. Y sin embargo..." (165) le gustaría poder cambiar pero ya no puede aceptar la inversión de los roles. Al final, Robinson vacila un instante en quedarse en la isla porque cree haber entendido a Viernes pero éste lo descarta subrayando su inutilidad en el mundo que ha creado en forma superficial:

VIERNES: -Demasiado tarde para ti, me temo. En Juan Fernández no hay lugar para ti y los tuyos, pobre Robinson Crusoe, pobre Alejandro Selkirk, pobre Daniel Defoe, no hay sitio para los náufragos de la historia, para los amos del polvo y el humo, para los herederos de la nada.

ROBINSON: -iY tú, Viernes?

VIERNES: -Mi verdadero nombre no es Viernes, aunque nunca te preocupaste por saberlo.Prefiero llamarme yo también Juan Fernández, junto con millones y millones de Juan Fernández que se reconocen como nos reconocemos Plátano y yo, y que empiezan a marchar juntos por la vida. (170)

En este diálogo, Viernes se erige como un ser dominante. No deja ningún lugar para la presencia de Robinson que pertenece a un pasado desconectado de la realidad presente. Alude a los tres protagonistas del mito: el personaje ficticio, el personaje real y el autor, con un dejo de compasión al nombrarlos. Viernes muestra un cierto rencor vengativo cuando subraya las violencias de la conquista al hablar de humo y de polvo. Europa dejó de ser primordial y es más bien prescindible. Viernes, a la vez que reafirma su identidad, la transforma en una voz comunitaria para todos los subalternos del mundo, para los hombres comunes y corrientes que tienen que unirse para crear una

Revista Iberoamericana, Vol. LXXIX, Núms. 244-245, Julio-Diciembre 2013, 843-862 ISSN 0034-9631 (Impreso) ISSN 2154-4794 (Electrónico) 
nueva esperanza y una nueva identidad que hace recordar a Los condenados de la tierra (1961) de Frantz Fanon. Robinson se queda definitivamente fuera de la historia porque no dimensiona la complejidad existente en las consecuencias de sus propias acciones.

IV. CONSOLIDACIÓN DE LA ALTERIDAD: PERMANENCIA DEL ENIGMA

1. Confusión en los lazos de dominación y problemática del mestizaje: subversión, inversión y alienación en Cortázar

En Cortázar, Viernes se rebela frente al imaginario de Robinson. Es también lúcido y pone en evidencia las consecuencias viciosas del camuflaje que ha adoptado al seguir el juego de Robinson. La pérdida de la autenticidad se hace presente en las acotaciones que muestran una isla convertida en una megalópolis común y ruidosa que podría representar, en cierta medida, la isla América Latina. El sociólogo chileno José Joaquín Brunner habla de la danza de los signos para ilustrar la fragmentación identitaria vivida por los latinoamericanos:

Nos movemos con la danza de los signos. Escuchamos su música, participamos de ella, vemos girar los cuerpos que bailan sin seguir un estilo ni denotar un patrón. Las figuras se quiebran al detenerse y vuelven a asumir su postura al recomenzar. Hay una sala de espejos donde se repiten, distorsionadamente, los desplazamientos de los bailarines. La luz intermitente desfigura los rostros; a ratos parecen máscaras y nada más. Quizá sea una fiesta popular... la caída de un dictador... O la muerte de un hermana. Nunca podemos estar completamente seguros. [...] Algunos espejos están trizados. $(1992,39-40)$

Los rostros enmascarados y los espejos trizados hablan de esa identidad escindida sufrida por Viernes y Plátano pero más aún por Nora, la verdadera mestiza. Viernes ha asimilado los códigos de la civilización británica sin haber renunciado a su identidad que surge cuando habla en su idioma original con Plátano.

\subsection{La isla: megalópolis posmoderna vulgar e indeterminada}

El blanqueamiento es un concepto que emerge de la voluntad de "limpiar" la raza india a través del mestizaje, de volverla más blanca. Ese "querer ser otro", ese enmascaramiento se ve plasmado en Nora y en la ciudad cosmética de Juan Fernández. Las acotaciones son reveladoras. Robinson ve la perfección de la modernidad mientras que en los intersticios del diálogo aparece otra visión de la ciudad: "Ruidos de calle, autos y gente que habla animadamente. Música idiota por altavoces que hacen propaganda comercial igualmente idiota" (157). Es una isla similar a otras porque perdió su identidad,

Revista Iberoamericana, Vol. LXXIX, Núms. 244-245, Julio-Diciembre 2013, 843-862 ISSN 0034-9631 (Impreso) ISSN 2154-4794 (Electrónico) porque la homogeneización emprendida por la modernidad aplacó la originalidad. La isla se convierte entonces un museo o una proyección de diapositivas (166) según Nora que sólo la puede ver desde el marco de la ventanilla de su auto. La isla no ha sido poblada. Sigue desierta porque es artificial, porque ningún habitante se siente realmente parte de ella. Es de fantasía porque carece de autenticidad, resultado de la globalización imperante. Surge una crítica a la modernidad en la pieza pero también una crítica a los que adoptaron sin pestañear y siguen aceptando esa suerte de neocolonialismo.

\subsection{Los mestizos culturales: Plátano y Viernes}

Viernes y Plátano deciden marcharse de la isla y adoptar el nombre de Juan Fernández ya que les arrebataron una vez su identidad. Juan Fernández es un nombre de pueblo que quieren adoptar en la búsqueda de un nuevo metarrelato ya que la modernidad y su capitalismo subyacente no son satisfactorios. Sin embargo, sería pertinente interrogarse sobre la motivación de elegir el nombre del explorador español que permitió el inicio de la colonización en la isla. Viernes no decide retomar su nombre original, decide ponerse otra máscara para vivir la transición de una identidad difícilmente discernible. Viernes vuelve con Plátano a Londres sin saber lo que le espera. Retorna al lugar de su aculturación pensando encontrar soluciones sin tener ninguna certeza: "No está claro Robinson. No está nada claro, créeme, pero digamos que van hacia tierra firme, digamos que quieren dejar para siempre atrás, las islas de los Robinsones, los pedazos solitarios de tu mundo" (170).

\section{Marginalización y aparición de la lucidez: la soledad en la multitud}

Robinson sufre una alienación y un rechazo conmiserativo. No lo acogen sino que lo toleran porque también encarna el dolor del traumatismo de la conquista: "Juan Fernández no es una colonia, señor Crusoe, y somos perfectamente dueños de nuestros sentimientos. Como comprenderá, no podíamos negarnos a su visita, puesto que usted ha vivido en nuestra isla y le ha dado un prestigio mundial, pero acaso no le extrañará saber que desde hace tiempo no permitimos la entrada a ningún extranjero" (155). La clausura hacia el exterior muestra también un problema de identificación. Si bien intenta compartir con su esclavo, nunca están en el mismo nivel (la habitación de Viernes "con una ventana que da a un agujero de ventilación" (158)). Robinson quiere y a la vez se siente rebajado al ponerse al nivel de Viernes que tampoco quiere compartir con él. Volviéndose lúcido, Robinson se aparta solo. Se resigna a no entender al otro y dejarlo a su suerte: "ROBINSON: Me alegro de volver a Inglaterra, Viernes. Me alegro de irme de la isla. No es mi isla. Creo que nunca fue mi isla, porque incluso entonces no entendí que [...] Es difícil explicarlo, Viernes, digamos que no entendí lo que hacía contigo, por ejemplo" (166). Robinson termina por abandonar su sentimiento de posesión de la isla

Revista Iberoamericana, Vol. LXXIX, Núms. 244-245, Julio-Diciembre 2013, 843-862 \begin{tabular}{ll}
\hline \hline ISSN 0034-9631 (Impreso) & ISSN 2154-4794 (Electrónico)
\end{tabular} 
y de Viernes. En Cortázar, Viernes expresa claramente por primera vez su versión de la historia. Sin embargo, al decidir tomar el nombre de Juan Fernández y no su nombre original, también muestra una actitud ambigua que muestra la confusión identitaria del cual es víctima. En realidad, en las robinsonnades posmodernas se cuestiona la noción de sujeto pero la figura de Robinson, degradada y disminuida, no abandona su soberbia y su aprehensión de la alteridad.

\section{CONCLUSIÓN}

El crítico Engélibert, al estudiar exhaustivamente las reescrituras contemporáneas de Robinson en el ámbito de la literatura francesa y anglosajona, da cuenta de la predominancia de la reflexión sobre el lugar del yo en las robinsonnades posmodernas. El individuo moderno que emergía en Robinson Crusoe de Daniel Defoe, en la encrucijada de las interrogaciones socio-económicas y religiosas deja lugar, en la posmodernidad, a la pérdida de la confianza del yo y a la ruptura del mismo doble lazo social. En Cortázar, Viernes opera una inversión de los roles y compadece a Robinson que representa una modernidad decadente. Es autónomo, flexible, adaptativo y finalmente complejamente triunfante. No se trata de un triunfo sobre la construcción de su lugar pero sí de una victoria sobre la posibilidad de la palabra. Viernes, en Cortázar, no es el esclavo mudo o silenciado de Daniel Defoe, de J.M. Coetzee, o de Michel Tournier. Es un personaje sagaz y reivindicativo. Robinson ya no tiene lugar en esta isla donde ya no hay más por construir o reconstruir. Viernes se desprende entonces del protagonista del mito cambiando su nombre al de Juan Fernández lo que ilustra una dificultad de definición identitaria que tiene implicaciones en cuanto al seguimiento del mito. En realidad, Cortázar parece plasmar en su obra una despedida definitiva al mito.

Las robinsonnades posmodernas constan en regla general de una pérdida de la identidad, de una ausencia de autonomía de Robinson que encarna el sujeto moderno por excelencia, y de la omnipresencia de la duda radical. Jean-François Lyotard, al reflexionar sobre el sujeto posmoderno, recalca que el nosotros ya no puede pretender a la universalidad y que hay que hacer el "deuil de l'émancipation universelle promise par la modernité [...], non seulement la perte de cet objet, mais la perte du sujet à qui cet horizon était promis" (43). Así, tanto el yo occidental representado por Robinson como el tu "indígena", "salvaje", o latinoamericano experimentan trastornos identitarios: "Les robinsonnades postmodernes sont "sans acception de personne", pour reprendre une formule de Genette: comment lire autrement la répétition et la réélaboration de l'histoire d'un naufragé deshumanisé, multiple, mis à mort ou cherchant son identité dans le "labyrinthe du doute" (Engélibert 329). En Cortázar, si bien Robinson está desorientado, se aferra a su pasado glorioso. Viernes experimenta más bien esa duda radical que lo obliga a refugiarse en lo que conoce, a adoptar un nombre ficticio, por

Revista Iberoamericana, Vol. LXXIX, Núms. 244-245, Julio-Diciembre 2013, 843-862 ISSN 0034-9631 (Impreso) ISSN 2154-4794 (Electrónico) su incapacidad momentánea a reinventarse.

Otro elemento me parece esencial recalcar: la transformación del sentimiento de culpabilidad del colonialista frente a sus acciones aniquiladoras en las colonias. En Defoe, la culpa es un elemento esencial pero no se aboca a la relación con Viernes sino que a su propia falta de obediencia a su padre y de fe en Dios. En las reescrituras, la culpabilidad se percibe esencialmente en el enfoque dado a la relación entre Robinson y Viernes. El tropo del canibalismo destacado por Carlos Jáuregui y reivindicado por Oswald de Andrade sigue vigente al evocar la libertad interior de Viernes ligada a su parte salvaje. En Cortázar, ya no es un buen salvaje pero tampoco lo había sido realmente en Defoe a pesar de su docilidad. En la obra del autor argentino, Robinson expresa explícitamente su culpa pero no logra ser totalmente sincero. Viernes no necesita ya la condescendencia y el sentimiento de culpa de Robinson ya que éste ha creado en realidad su propia desgracia y su propia inmovilidad. Las reescrituras en general y ésta en particular recalcan la visión de un Robinson confundido, estático, y de un Viernes flexible y en constante movimiento. La alteridad no cesa de alterarse y de regenerarse en esa capacidad metamórfica.

\section{BiBLIOGRAFíA}

Affergan, Francis. “Les Marqueurs de l'autre dans Robinson Crusoe: Contribution a la genèse de l'anthropologie de l'altérité". Temps Modernes 44/507 (1988): 23-45.

Andrade, Oswald de. Escritos antropófagos. Buenos Aires: Corregidor, 2001.

Bergson, Henri. "Le Rire. Essai sur la signification du comique". CEuvres, Edition du Centenaire. André robinet, notas. Henri Gouthier, introducción. Paris: PUF, 1959.

Bhabha, Homi K. El lugar de la cultura. 1994. CésarAira, trad. Buenos Aires: Manantial, 2002.

Brunner, José Joaquín. “La ciudad de los signos”. América Latina: Cultura y modernidad. México, DF: Grijalbo, 1992.

Carrera, Patricia. Análisis del radioteatro a través de la obra de Julio Cortázar: "Adiós, Robinson”, tesis de master en Letras Hispánicas, Université de Montréal, abril 2010. <https://papyrus.bib.umontreal.ca/jspui/bitstream/1866/4396/2/Carrera Silvia P 2010 memoire.pdf.pdf>.

Cortázar, Julio. Nicaragua, tan violentamente dulce. Barcelona: Muchnik Editores, 1983. "Carta a Roberto Fernández Retamar". Colección Unesco de obras representativas. Serie Iberoamericana. Madrid: Santillana, 1994.

Adiós, Robinson y otras piezas breves. Buenos Aires: Alfaguara, 1995.

Defoe, Daniel. Robinson Crusoe. Prólogo de J. M. Coetzee. Julio Cortázar, trad. Barcelona: DeBolsillo, 2008.

Engélibert, Jean-Paul. La Postérité de Robinson Crusoé: un mythe littéraire de la modernité. 1954-1986. Genève: Droz, 1997.

Revista Iberoamericana, Vol. LXXIX, Núms. 244-245, Julio-Diciembre 2013, 843-862 ISSN 0034-9631 (Impreso) $\quad$ ISSN 2154-4794 (Electrónico) 
Genette, Gérard. Palimpsestes: La littérature au second degré. Paris: Seuil, 1982.

Hulme, Peter. "Robinson Crusoe and Friday". Colonial Encounters: Europe and the Native Caribbean, 1492-1797. New York: Methuen, 1986. 175-222.

Jameson, Frederic. El posmodernismo o la lógica cultural el capitalismo avanzado. Barcelona: Paidós, 1991.

Jáuregui, Carlos A. Canibalia: canibalismo, calibanismo, antropofagia cultural y consumo en América Latina. Madrid: Iberoamericana Editorial Vervuert, 2008.

Lévinas, Emmanuel. Éthique et Infini. Paris: LGF - Livre de Poche, 1984.

Lyotard, Jean-François. Le Postmoderne expliqué aux enfants. Paris: Hachette, 1994.

Moura, J.M. Lire l'exotisme. Paris: Dunod, 1993.

Terrero, Patricia. "El radioteatro". Artistas y espectáculos. Buenos Aires: Centro Editor de América Latina, 1985. 1-20.

Todorov, Tzvetan, La conquista de América. La cuestión del otro. México: Siglo XXI, 1987.

Watt, Ian. "Robinson Crusoe', Individualism and the Novel." The Rise of the Novel: Studies in Defoe, Richardson, and Fielding. London: U of California P, 1957. 60-92. 